\title{
A INCORPORAÇÃO DE BIM NO ENSINO DO CURSO TÉCNICO EM EDIFICAÇÕES
}

\author{
INCORPORATION OF BIM IN BUILDING CONSTRUCTION \\ TECHNICIAN COURSE
}

\author{
Marcio de Oliveira Cruz', Ana Regina Mizrahy Cuperschmid', Regina Coeli Ruschel ${ }^{2}$
}

RESUMO: A necessidade de inserir no mercado técnicos qualificados na produção de modelos de informação da construção, extração de dados, detecção de interferências e outras ações relacionadas ao Building Information Modeling (BIM), fez com que a escola Senai Orlando Laviero Ferraiuolo buscasse meios para incorporá-lo ao ensino. Tendo em vista o objetivo de inserção da formação em BIM a nível básico, iniciou-se uma investigação das barreiras para a adoção deste processo no curso e, paralelamente, adotou-se a utilização de estratégias para a incorporação do conteúdo em um conjunto abrangente de disciplinas. Neste artigo busca-se relatar o procedimento de diagnóstico das barreiras para adoção de BIM realizado e o processo simultâneo de ações para incorporação de BIM. Para apoiar este diagnóstico, foi adotado o método de pesquisa etnográfica. Esta investigação foi desenvolvida em dois ciclos: no primeiro, aplicou-se o método de diagnóstico de Checcucci, em formato de entrevista em profundidade juntamente com a observação participante; no segundo, adaptou-se o método para o formato de levantamento, por meio de um questionário online. Com esta pesquisa foi possível descrever elementos da organização no contexto da incorporação de BIM na formação do técnico de edificações. Os elementos caracterizados foram a transformação na estrutura curricular e a percepção do corpo docente sobre as barreiras associadas. As contribuições deste trabalho são o registro do processo e diagnóstico de implementação de BIM no curso Técnico em Edificações, as ações que possibilitaram o amadurecimento do conhecimento dos professores e a adaptação do método de Checcucci para diagnóstico da permeabilidade da inserção de BIM em estruturas curriculares.

\section{PALAVRAS-CHAVE: BIM; Ensino; Diagnóstico; Curso Técnico em Edificações.}

ABSTRACT: The market need to introduce qualified technicians in the production of virtual models of buildings, data extraction, clash detection, and other actions related to Building Information Modeling (BIM), has made the Senai Orlando Laviero Ferraiuolo school seek means to incorporate it into teaching. Considering the objective to insert BIM education at basic level, an investigation was developed about the barriers to adopting BIM in the course and, at the same time, we used strategies to incorporate content into a comprehensive set of disciplines. This paper aims to report the procedure for diagnosing barriers to adopting BIM and simultaneous processes for incorporating BIM. To support this research, the method of ethnographic research was adopted, which was developed in two cycles: in first, the Checcucci diagnostic method was applied in an in-depth interview format along with participant observation; in the second one, the method was adapted for the survey format, through an online questionnaire. With this research, it was possible to describe elements of the organization, in the context of BIM incorporation in the training of building construction technicians. The elements characterized were the transformation in curricular structure and the perception of the faculty on associated barriers. This work's contributions are the registration of the process and diagnosis of BIM implementation in Building Construction Technician course, the actions that enabled the maturation of teachers' knowledge and adaptation of the Checcucci method to diagnose the permeability of BIM insertion in the syllabus.

KEYWORDS: BIM; Teaching; Diagnostics; Building Construction Technician Course.

\section{How to cite this article:}

CUPERSCHMID, A.; CRUZ, M. O.; RUSCHEL, R. C. A incorporação de BIM no ensino do curso Técnico em Edificações. Gestão \& Tecnologia de Projetos, São Carlos, v. 12, n. 2, p. 117-134. 2017. http://dx.doi.org/10.11606/gtp. v12i2.131498

Fonte de financiamento: Coordenadoria de Aperfeiçoamento de Pessoal de Nível Superior (CAPES). Conflito de interesse: Declaram não haver Submetido em: 23/04/2017 Aceito em: 23/06/2017 


\section{INTRODUÇÃO}

O curso Técnico em Edificações visa formar profissionais atuantes no gerenciamento de serviços de obras e na produção de projetos técnicos, sempre com a supervisão de engenheiros e arquitetos. O curso Técnico em Edificações do Serviço Nacional de Aprendizagem Industrial (Senai) tem foco na aprendizagem por competência, fazendo com que os alunos vivenciem os problemas que ocorrem em sua área de trabalho por meio de atividades práticas e resolução de problemas reais.

O Senai é um sistema de ensino profissional com base federativa, que busca atender as necessidades de qualificação de mão de obra para o mercado. A instituição é mantida por meio de um decreto federal que estabelece a destinação de $0,5 \%$ da folha de pagamento da indústria para o Senai. No estado de São Paulo, existem apenas duas unidades que oferecem o curso Técnico em Edificações, a Escola Senai "Orlando Lavieiro Ferraiuolo" (Unidade 1.11), situada na capital, e a Escola Senai "João Martins Coube" (Unidade 7.01), em Bauru.

A escola Senai "Orlando Lavieiro Ferraiuolo" foi inaugurada em 1959, mas somente em 1994 foi implementado o curso técnico modularizado de três anos, com os cursos de Auxiliar Técnico e Desenhista de Construção Civil, que em 2001, passou a ser chamado de Técnico em Edificações. Esse curso tem duração de dois anos e possui entrada de novos alunos a cada semestre, ao final do terceiro semestre, o aluno recebe duas certificações intermediárias de "Desenhista de edificações" e "Laboratorista de ensaios de materiais de edificações”, aumentando suas possibilidades de inserção no mercado de trabalho. A Figura 1 exibe a estrutura curricular adotada até 2016.

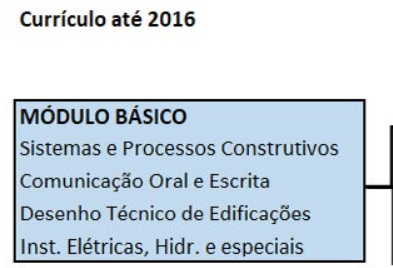

Figura 1: Estrutura curricular do curso Técnico em Edificações até 2016

Fonte: baseado em Senai, 2013

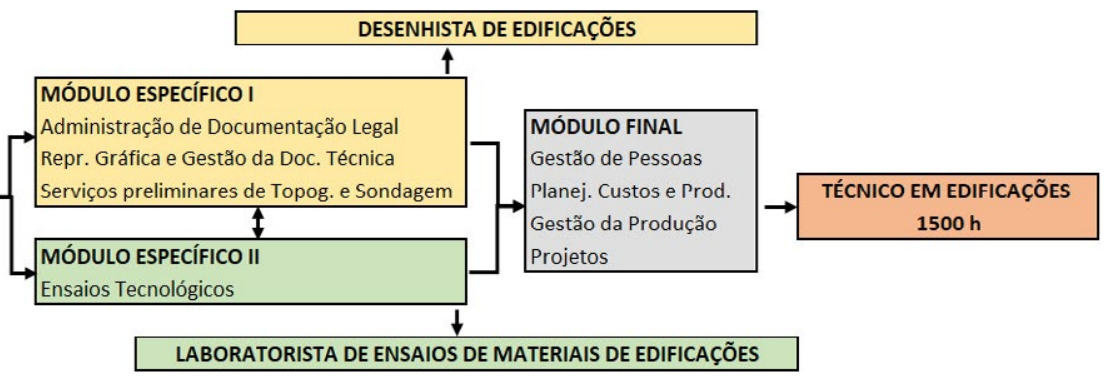

Por semestre entram 96 alunos distribuídos entre manhã, tarde e noite. Os alunos dos períodos diurnos têm faixa etária em torno de 18 anos e, do noturno, têm faixa etária variada, entre 18 e 65 anos. A escola conta hoje, com o efetivo de 86 funcionários e, destes, aproximadamente dezesseis atuam como docentes do curso Técnico em Edificações.

Em novembro de 2013, um professor da unidade "Orlando Lavieiro Ferraiuolo", que também é um dos autores deste artigo, juntamente com o diretor da unidade e uma comissão da Federação das Indústrias do Estado de São Paulo (Fiesp) viajaram para visitar a Batimat Paris e lá tiveram o primeiro contato com a metodologia BIM. Neste evento, o diretor da unidade modificou o plano de ensino do curso técnico, incluindo fundamentos sobre a metodologia na disciplina de "Representação Gráfica e Documentação Técnica”. Em junho de 2014, foi formada nova comissão, desta vez com intuito exclusivo de vislumbrar como o processo de Building Information Modeling (BIM) estava sendo adotado na indústria da construção civil na Europa. A modificação do currículo só foi concretizada oficialmente em 2015, após o período de análise da gerência de educação do Senai-SP. Esta experiência inicial abriu novas possibilidades de inserção de BIM em outras disciplinas. 
Checcucci (2014) segmenta as competências mínimas necessárias para a formação de alunos em três níveis: básico, intermediário e avançado. O Senai desejava formar alunos com competência básica em BIM que, de acordo com a professora, abrange os conteúdos: conceitos relacionados ao BIM; modelagem básica de componentes e habilidade para trabalhar com pelo menos uma ferramenta de modelagem de projeto; comunicação utilizando diferentes meios de expressão; 4D e conceitos de simulação utilizando modelos BIM; extração de informações simples do modelo, como quantitativos e representações da edificação.

Tendo em vista acompanhar a inserção da formação em BIM no curso Técnico em Edificações do Senai a nível básico, desenvolveuse uma investigação simultânea para a identificação das barreiras desta transformação. Este artigo apresenta o diagnóstico das barreiras encontradas e a transformação obtida das ações para incorporação de BIM no curso Técnico em Edificações do Senai.

\section{FUNDAMENTAÇÃO}

Succar (2009) aprimora a definição de BIM de Penttilä (2006), esta definição aprimorada é adotada pela Câmara Brasileira da Indústria da Construção (CBIC) (2016), sendo apresentada a seguir:

BIM é um conjunto de políticas, processos e tecnologias que, combinados, geram uma metodologia para gerenciar o processo de projetar uma edificação ou instalação e ensaiar seu desempenho, gerenciar as suas informações e dados, utilizando plataformas digitais, através de todo seu ciclo de vida (p. 22).

Segundo Ghaffarianhoseini et al. (2017), os benefícios resultantes da adoção de BIM são: técnicos, de gestão do conhecimento, de padronização, de diversidade de aplicação, de integração, econômicos, de planejamento, de Análise do Ciclo de Vida (ACV) e de suporte à tomada de decisão. Diferentes benefícios são apropriados de acordo com o interveniente (EASTAMN et al., 2011). Além disto, estes benefícios são apropriados em graus variados dependendo do tamanho da empresa, do país, das normas para a educação (GHAFFARIANHOSEINI et al., 2017) e do engajamento (MCGRAW-HILL CONSTRUCTION, 2014, p. 5).

A construção civil mundial e brasileira tira proveito financeiro da adoção de BIM. O retorno do investimento é um dos fatores motivadores do aceite pela indústria ao desafio que é incorporar BIM. O relatório The bussiness value of BIM for constructions in major global markets que avaliou América do Norte, Brasil, Europa, Coréia do Sul, Japão, Austrália e Nova Zelândia aponta que no Brasil os empreiteiros indicaram um retorno de $85 \%$ nos investimentos em BIM, apesar de, em sua maioria (70\%), terem adotado a tecnologia em menos de dois anos (MCGRAW-HILL CONSTRUCTION, 2014, p. 46-47). Entretanto, o Brasil, a Coréia do Sul e o Reino Unido indicaram o menor nível de satisfação na proficiência em BIM, o que está diretamente ligado ao baixo nível dos usuários no tocante à experiência, habilidade e implementação. Esses dados indicam uma demanda por profissionais qualificados em BIM no mercado nacional.

Succar, Sher e Williams (2012) apontam que para capacitar indivíduos a desenvolver suas habilidades em BIM, é importante identificar as competências que precisam ser aprendidas, aplicadas no trabalho, e mensuradas para fins de melhoria de desempenho. Neste sentido, os cursos ligados à área de Arquitetura, Engenharia e Construção (AEC) precisam que novas habilidades e conhecimentos sejam disseminados para a adoção de BIM em seu currículo. Várias pesquisas trataram do ensino de BIM nas universidades brasileiras (RUSCHEL; ANDRADE; MORAIS, 2013; BARISON, 2015; CHECCUCCI; AMORIM, 2016; RUSCHEL, 2014). 
Ruschel, Andrade e Morais, (2013) avaliaram como está sendo feita a introdução de BIM nos cursos de Arquitetura e Engenharia Civil no país e compararam com abordagens de ensino no panorama internacional. Para sua maior adoção, os autores sugerem que os professores das universidades devem compreender o conceito de BIM e implementar uma revisão da estrutura das grades curriculares tendo em vista conceitos como coordenação, integração e colaboração.

Barison (2015, p.2 99) aponta que, no Brasil, "os estudantes ainda não estão sendo preparados para ingressar no mercado de trabalho com conhecimentos e habilidades em BIM". Em sua tese, levanta algumas possíveis causas como a falta de espaço nos currículos e a falta de conhecimento dos professores em relação ao significado do processo BIM. A autora expõe que uma forma de compensar a falta de espaço para novas disciplinas é a introdução de conteúdos BIM em diversas disciplinas. Para tanto, foi desenvolvido um questionário online que, após preenchido pelos professores, oferece recomendações para adoção de BIM.

Checcucci e Amorim (2016) apresentam um método que objetiva identificar as interfaces existentes entre BIM e os cursos de graduação, buscando identificar as ocasiões em que os componentes curriculares podem ser discutidos e trabalhados. Para tanto, é utilizado um sistema de representação para registrar as análises das ementas das disciplinas, nele são utilizadas cores e gradações para demonstrar o grau de interface que a disciplina tem com o paradigma BIM.

Ruschel (2014) destaca que para que os modelos de concepção digital (formativo, generativo e baseado em desempenho) mediados por BIM sejam implementados no ensino de arquitetura, faz-se necessário incluir questões referentes à interoperabilidade e tradução de modelos junto com desenvolvimento de projeto de maneira integrada e colaborativa. A autora também acrescenta como crucial a compreensão teórica de BIM por parte dos professores e "uma revisão na estrutura das grades curriculares, com a criação de eixos verticais e horizontais de conhecimentos atrelados ao BIM" (RUSCHEL, 2014).

Internacionalmente, Sacks e Pikas (2013) propõem um modelo para adoção de BIM que explicita tópicos necessários e níveis a serem alcançados a cada estágio da formação de profissionais no campo de AEC. O ponto de partida foi o estabelecimento dos requisitos na indústria para profissionais. Em seguida, definiu-se a lacuna entre os requisitos e o atual estágio de adoção de BIM na formação desses profissionais. Os autores estabeleceram 39 tópicos para incorporação de BIM no currículo, segmentados em três áreas de competências que envolvem processos, tecnologia e aplicação.

Kymmell (2008 apud BARISON; SANTOS, 2011) ressalta que a introdução de BIM no currículo dos cursos envolve três tipos de obstáculos possíveis: circunstâncias do ambiente acadêmico - considerando a questão de tempo, motivação, recursos, regras e currículo; incompreensão dos conceitos de BIM - discutindo o ensino individualizado e o tradicional, a importância do trabalho em equipe e da colaboração e dificuldades de aprendizagem e de utilização das ferramentas BIM. Tendo em vista esses obstáculos, delineouse uma estratégia para realização da pesquisa e implementação do BIM no curso, descrita em seguida.

\section{METODOLOGIA}

Para apoiar esta investigação, foi adotado o método de pesquisa etnográfica. De acordo com Gil (2010), este método é utilizado para descrição dos elementos de uma organização específica, baseado em informações coletadas mediante trabalho de campo. Este método de pesquisa fundamentase num pequeno número de casos e envolve entrevistas em profundidade, observação participante e análise de documentos (GIL, 2010). Buscou-se 
qualificar barreiras culturais, técnicas e pedagógicas associadas ao esforço de implementação da modelagem da informação na construção no ensino e, desta forma, contribuir para a inovação e aproximação com a prática.

Desta forma, a pesquisa etnográfica adotou o delineamento especificado por Gil (2010), que envolve as etapas de: formulação do problema; seleção da amostra; entrada em campo; coleta de dados; elaboração de notas de campo e análise dos dados. Esse projeto foi realizado em dois ciclos: no primeiro aplicou-se o método de diagnóstico de Checcucci (2014) em formato de entrevista em profundidade e observação participante, e no segundo adaptou-se o método para o formato de levantamento. 0 primeiro ciclo da pesquisa envolveu professores de algumas disciplinas do curso e o segundo envolveu pelo menos um professor de todas as disciplinas. A Figura 2 resume os dois ciclos de pesquisa desenvolvidos.

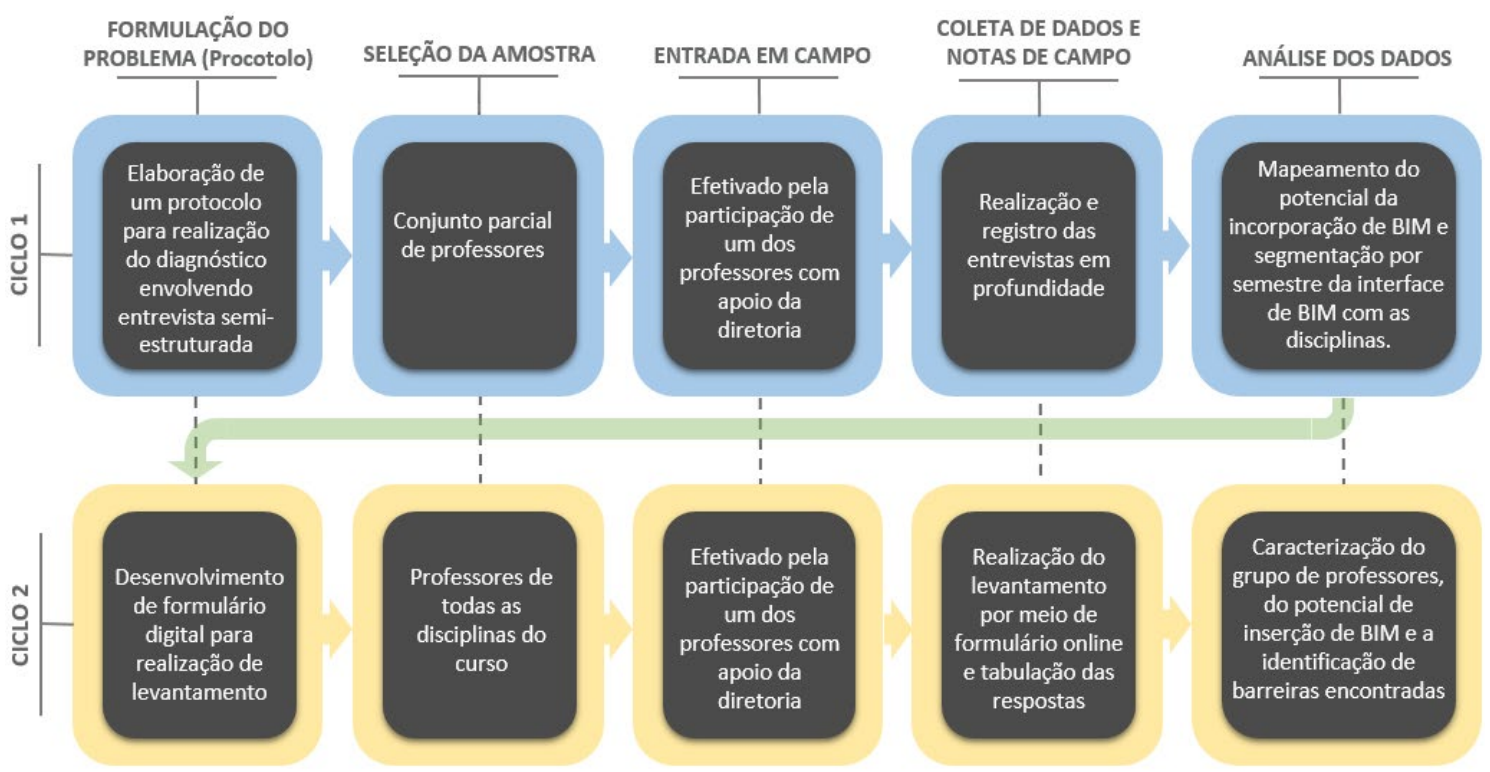

A forma com que o método de diagnóstico de Checcucci (2014) foi apropriado em formato de entrevista ou adaptado para levantamento é apresentado conjuntamente com os resultados.
Figura 2: Processo metodológico adotado na pesquisa

Fonte: os autores

\section{DESENVOLVIMENTO E RESULTADOS}

\section{Ciclo 1}

A elaboração de protocolo para realização de diagnóstico para avaliar as barreiras para a incorporação no ensino do curso Técnico em Edificações foi a primeira etapa dessa pesquisa. Para diagnosticar a aceitação dos professores do curso técnico em relação à adoção de BIM no ensino, buscouse utilizar técnicas de interrogação para obter dados a partir do ponto de vista dos pesquisados (GIL, 2010), no caso, os docentes. Inicialmente, optouse pela utilização de entrevistas, em que o pesquisador formulava questões previamente elaboradas e anotava as respostas em uma situação "face a face" (GIL, 2010).

A parte inicial da entrevista visava identificar a disciplina, a formação acadêmica do professor, o tempo de experiência na área, o turno da disciplina, o tempo de atuação na disciplina e a quantidade de professores 
envolvidos na mesma disciplina. Em seguida, os entrevistados eram averiguados em relação ao interesse sobre o tema BIM e o interesse em aplicá-lo na disciplina que lecionava (opções de resposta: não tenho interesse nenhum; não tenho interesse; não formei opinião a respeito; me interessa; tenho muito interesse). Em caso de falta de interesse, a pesquisa não prosseguia.

A segunda parte era voltada a identificar o potencial de inserção do BIM na disciplina. As questões foram baseadas na pesquisa desenvolvida por Checcucci e Amorim (2016), Quadro 1. As alternativas possíveis de resposta eram: não existe interface com o tema; pode haver interface, a depender do foco que o professor dê para a disciplina; existe uma interface clara com o paradigma BIM.

Quadro 1: Segunda etapa da entrevista: potencial de inserção de BIM na disciplina

\begin{tabular}{|c|}
\hline 2.1. Sobre a relação componente curricular (da sua disciplina) x BIM, você entende que: \\
\hline 2.2 A disciplina deveria trabalhar com algum conceito importante do BIM? \\
\hline 2.2.1. A disciplina deveria abordar BIM relacionado ao Ciclo de Vida da Edificação? \\
\hline 2.2.2. A disciplina deveria abordar BIM relacionado à colaboração? \\
\hline 2.2.3. A disciplina deveria abordar BIM relacionado à interoperabilidade? \\
\hline 2.2.4. A disciplina deveria abordar BIM relacionado à coordenação do processo de modelagem? \\
\hline 2.2.5. A disciplina deveria abordar BIM relacionado à modelagem geométrica tridimensional? \\
\hline 2.2.6. A disciplina deveria abordar BIM relacionado à parametrização? \\
\hline 2.2.7. A disciplina deveria abordar BIM relacionado à orientação a objetos? \\
\hline 2.2.8. A disciplina deveria abordar BIM relacionado à semântica do modelo? \\
\hline 2.2.9. A disciplina deveria abordar BIM relacionado à visualização do modelo? \\
\hline 2.2.10. A disciplina deveria abordar BIM relacionado à simulação e análise numérica? \\
\hline 2.3. A disciplina deveria trabalhar com BIM em alguma etapa do ciclo de vida da edificação? \\
\hline 2.3.1. A disciplina deveria abordar BIM relacionado ao estudo de viabilidade? \\
\hline 2.3.2. A disciplina deveria abordar BIM relacionado à projetação? \\
\hline 2.3.3. A disciplina deveria abordar BIM relacionado ao planejamento da construção? \\
\hline 2.3.3. A disciplina deveria abordar BIM relacionado à construção? \\
\hline 2.3.4. A disciplina deveria abordar BIM relacionado ao uso: operação/manutenção? \\
\hline 2.3.5. A disciplina deveria abordar BIM relacionado à demolição ou requalificação? \\
\hline 2.4. A disciplina (que você leciona no curso) deveria trabalhar algum projeto utilizando BIM? \\
\hline 2.4.1. A disciplina deveria trabalhar com projeto de arquitetura utilizando BIM? \\
\hline 2.4.2. A disciplina deveria trabalhar com projeto de estrutura utilizando BIM? \\
\hline 2.4.3. A disciplina deveria trabalhar com projeto de elétrica utilizando BIM? \\
\hline 2.4.4. A disciplina deveria trabalhar com projeto de hidráulica utilizando BIM? \\
\hline 2.4.5. A disciplina deveria trabalhar com projeto de ar condicionado utilizando BIM? \\
\hline 2.4.6. A disciplina deveria trabalhar com outro projeto utilizando BIM? Especifique: \\
\hline
\end{tabular}

Fonte: baseado em Checcucci, 2014

Conforme estabelecido por Checcucci (2014), o resultado deste questionário serviria como input para o preenchimento de campos com cores identificando, em cada disciplina, como cada item era avaliado de acordo com seu potencial de inserção de BIM (Figura 3). 


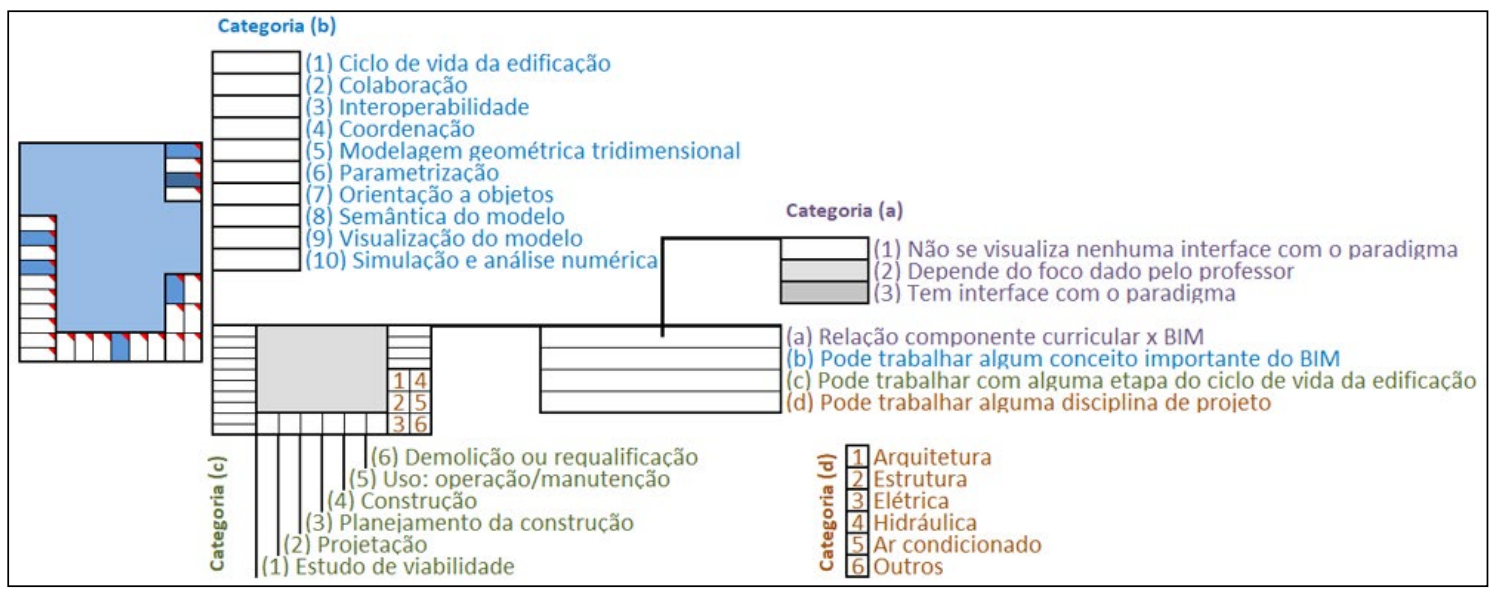

Figura 3: Modelo de preenchimento do gráfico, conforme proposto por Checcucci

$\mathrm{Na}$ terceira etapa da entrevista, foram realizadas perguntas para identificar as barreiras e anseios dos professores no tocante à adoção de BIM (Quadro 2).

Fonte: Gráfico (esquerda): os autores, campos a serem preenchidos (direita): Checcucci, 2014

Quadro 2: Terceira etapa da entrevista: identificação de barreiras e anseios dos professores

\begin{tabular}{|c|}
\hline 3.1. Indique as dificuldades que você sente para inserir a metodologia BIM na sua disciplina: \\
\hline $\begin{array}{l}\text { ( ) Falta de conhecimento aprofundado sobre os conceitos de BIM. ( ) Falta de conhecimento específico sobre BIM } \\
\text { relacionado à disciplina. ( ) Tenho dificuldade de utilizar de programas BIM. ( ) Necessito de auxílio para a implementação de } \\
\text { BIM na disciplina. ( ) Tenho dificuldade em escolher qual ferramenta BIM utilizar. ( ) Falta de tempo para preparação de aulas } \\
\text { que abordem BIM. ( ) A carga horária não comporta abordar este assunto. ( ) Falta computadores para todos os alunos. ( ) } \\
\text { A ementa da disciplina não é adequada, em termos de conteúdos e metodologia. ( ) Seria necessário que o aluno tivesse } \\
\text { cursado outra disciplina como pré-requisito ( ) Seria necessário o pré-requisito de conhecimento do aluno em }\end{array}$ \\
\hline 3.2. Indique as dificuldades que você sente para inserir BIM no curso Técnico em Edificações: \\
\hline $\begin{array}{l}\text { ( ) Falta de professores capacitados. ( ) Dificuldades na compreensão dos conceitos e no aprendizado de programas. ( ) } \\
\text { Resistência cultural à mudança de paradigma. ( ) Infraestrutura inadequada. ( ) Alto custo da tecnologia impede sua adoção. } \\
\text { ( ) Falta de tempo para montar um novo currículo. ( ) Falta de espaço na matriz curricular para inserir novas disciplinas. ( ) } \\
\text { Falta de bibliografia específica sobre o tema no contexto nacional. ( ) Falta de interação e colaboração entre os professores, } \\
\text { coordenação e direção da escola. ( ) Falta de tempo necessário para amadurecer o currículo, promovendo melhorias no } \\
\text { curso e revisando as experiências realizadas. }\end{array}$ \\
\hline 3.3. Qual sua sugestão para solucionar as dificuldades na inserção da metodologia BIM apontadas por você no item acima? \\
\hline $\begin{array}{l}\text { ( ) A coordenação pedagógica deve estabelecer e divulgar o objetivo da adoção do BIM no curso. ( ) A coordenação pedagógica } \\
\text { deve planejar, executar, verificar e tomar ações corretivas no que se refere à adoção de BIM. ( ) Participação em eventos que tratem } \\
\text { o assunto BIM (palestras, workshops, congressos). ( ) Realização de cursos na internet. ( ) Realização de cursos presenciais. ( ) } \\
\text { Acompanhamento pedagógico periódico do desenvolvimento dos projetos que envolvam BIM. ( ) Os alunos deveriam desenvolver } \\
\text { projetos interdisciplinares, de forma a propiciar o aprimoramento do projeto no decorrer do curso. ( ) Propiciar campeonatos e } \\
\text { concursos de projetos BIM. ( ) Disponibilizar material didático atualizado para os alunos e professores. ( ) Outros: }\end{array}$ \\
\hline
\end{tabular}

Fonte: baseado em Checcucci, 2014, e Barison, 2015

A coleta de dados aconteceu durante o mês de agosto de 2016 na própria escola. Para a execução das entrevistas em profundidade, o pesquisador realizava as questões previamente elaboradas (Quadros 1 e 2) e anotava as respostas dadas pelos professores. Este procedimento foi realizado em uma sala, de forma individual, com nove professores de disciplinas diferentes.

Realizada a entrevista com docentes, foram preenchidos os campos de acordo com a forma gráfica proposta por Checcucci (2014) (Figura 4). Verificou-se que ao serem questionados sobre o potencial de inserção de BIM, a maioria dos professores respondeu positivamente para todas as possibilidades de inserção na disciplina. Grande parte dos entrevistados afirmou ter potencial para trabalhar com BIM, em sua disciplina, 
abrangendo todas as etapas do ciclo de vida da edificação. Isto demonstrou falha na forma com que as questões foram formuladas. Ademais, observouse que os professores tiveram dificuldades no entendimento dos conceitos relacionados ao BIM (Quadro 1: item 2.2).

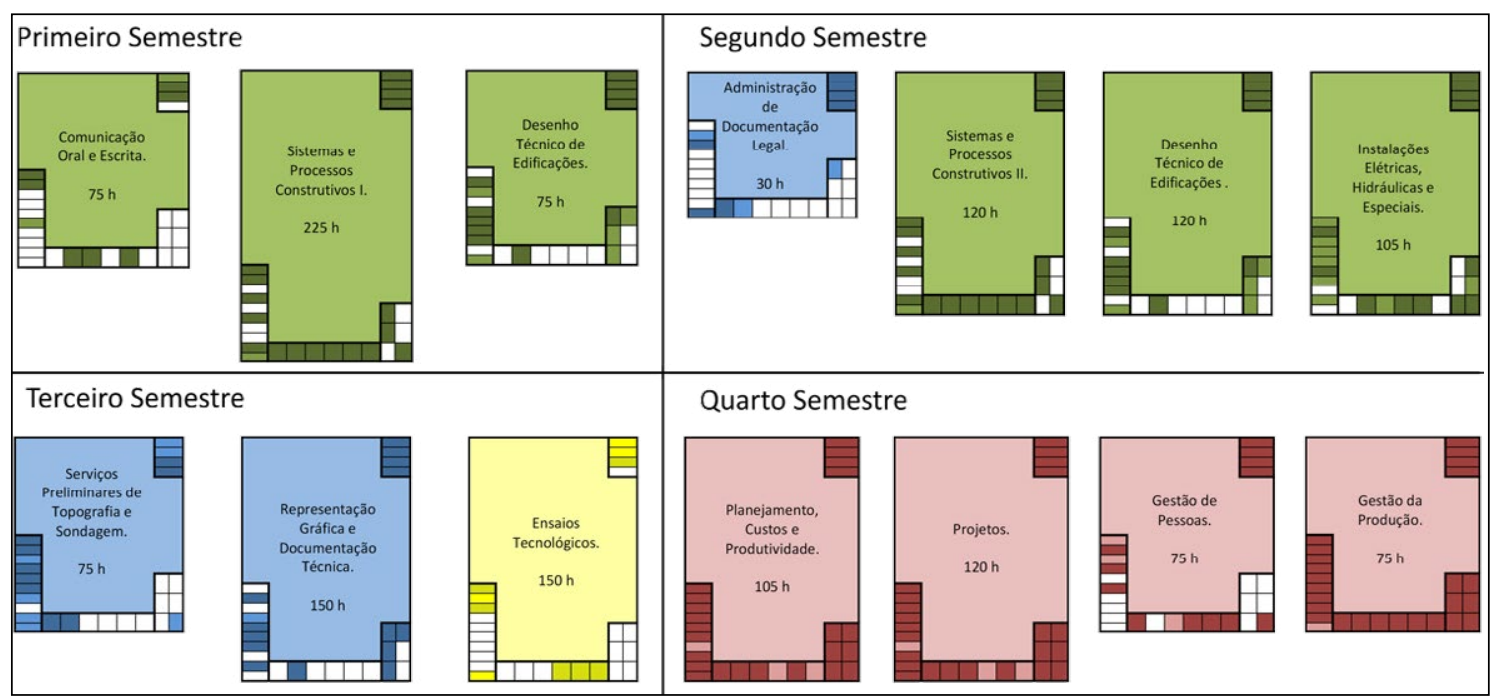

Figura 4: Gráficos das disciplinas segmentadas por semestre

Fonte: os autores

A visualização dos dados obtidos nesse formato se mostrou insatisfatória para a análise comparativa das informações. Desta forma, os pesquisadores buscaram uma maneira de realizar gráficos comparativos por semestres, na forma de roscas e barras. Comparando-se as diversas formas gráficas conseguimos perceber que a proposta por Checcucci (2014) contém diversas informações importantes e setorizadas. Em contrapartida, o gráfico de rosca e o gráfico de barras (Gráfico 1), facilitam a comparação mas não possibilitam visualizar itens específicos, como os dados por disciplina. Os resultados preliminares indicaram maior potencial de interface com BIM no quarto semestre, seguido pelo segundo, sendo que o terceiro semestre demonstrou menor interface com o BIM.

Gráfico 1: Gráficos de indicação da interface com BIM das disciplinas (compiladas por semestre): rosca (esquerda), barras (direita)
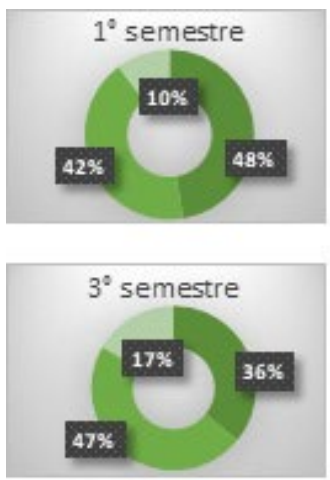

Fonte: os autores
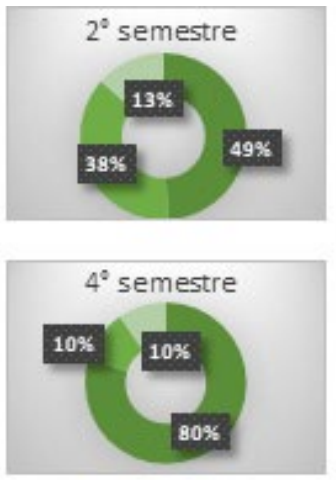

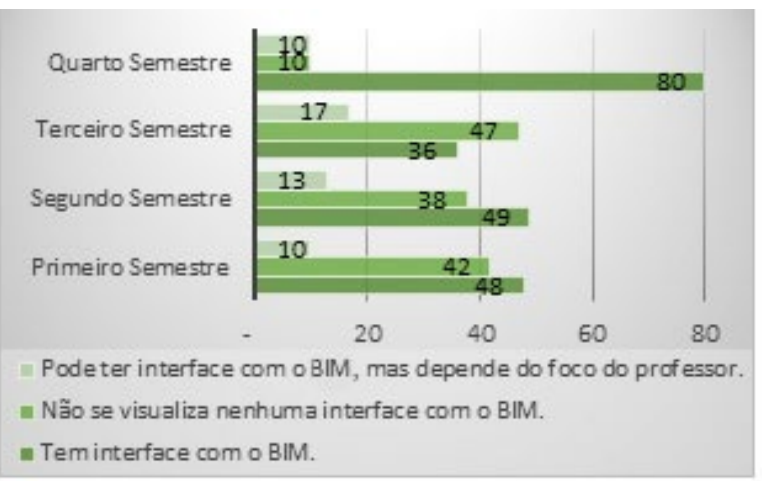

Alguns comentários realizados durante a coleta de dados devem ser destacados. Um dos professores declarou que "não é possível implementar BIM na escola, nem no Brasil", este tipo de pensamento denota a necessidade de maior compreensão sobre o assunto e os diversos graus de adoção do processo que podem ser realizados. O mesmo se pode dizer de outro professor que afirmou "O BIM é igual ao PLM (Product Lifecycle 
Management) que já é feito na indústria automobilística a muito tempo e eu conheço muito bem, mas na nossa área será muito difícil de se implantar esse sistema”. A relação entre BIM e o PLM mostra a capacidade do professor em correlacionar os processos, segundo o CBIC (2016, p. 23), "soluções similares ao BIM têm sido utilizadas em diversas indústrias, onde a complexidade logística ou repetição de um mesmo projeto exigiam e permitiam um maior investimento no desenvolvimento dos projetos e especificações”. Entretanto, a forma como o professor se expressou denota percepção de barreiras para a adoção pela construção civil.

Dadas as dificuldades no entendimento das questões e de conceitos BIM, optou-se por reformular as questões e inserir informações sobre os conceitos averiguados, dando início ao Ciclo 2 da pesquisa.

\section{Ciclo 2}

Devido às dificuldades encontradas no Ciclo 1, fez-se necessário reformular as questões. Nesta nova versão, optou-se por realizar um questionário on-line, em que um conjunto de questões eram respondidas por escrito pelos pesquisados (GIL, 2010). Na primeira etapa, acrescentou-se a opção de selecionar a disciplina lecionada, a carga horária correspondente e os semestres em que a disciplina ocorria no curso.

Na segunda etapa do questionário, optou-se por identificar a atual situação da disciplina no tocante às etapas do ciclo de vida que são abordadas e ao tipo de projeto que é trabalhado na disciplina, independente do uso do BIM. Com isso, a incorporação de BIM seria, então, focada no que a disciplina aborda realmente. Dessa maneira, as questões 2.3 e 2.4 foram reformuladas (Quadro 3).

Quadro 3: Alteração no questionário para avaliar o potencial de inserção de BIM na disciplina: questões reformuladas 2.3 e 2.4

2.3 A disciplina aborda alguma etapa do ciclo de vida da construção? Qual(is)?

( ) estudo de viabilidade; ( ) projetação; ( ) planejamento da construção; ( ) construção; ( ) operação/ manutenção; ( ) demolição ou requalificação.

2.4 Esta disciplina desenvolve algum tipo de projeto? Qual(is) tipo(s) de projeto(s) a sua disciplina trabalha?

( ) arquitetura; ( ) projeto de estrutura; ( ) projeto de elétrica; ( ) projeto de hidráulica; ( ) ar condicionado; ( ) outro projeto, qual?

Fonte: adaptado de Checcucci, 2014

No item 2.2, para facilitar a compreensão dos professores e nivelar o entendimento quanto aos conceitos BIM averiguados, foram acrescentadas definições e exemplos referentes a cada conceito (Quadro 4).

Quadro 4: Exemplo de questão para avaliar o potencial de inserção de BIM, com conceito explicitado

2.2 A disciplina deveria trabalhar com algum conceito importante do BIM?

2.2.1. A disciplina deveria abordar BIM relacionado ao Ciclo de Vida da Edificação?

[CICLO DE VIDA é definido como o período desde as fases mais iniciais da concepção de um edifício, passando pela construção, manutenção e até a sua reforma ou demolição].

Fonte: adaptado de Checcucci, 2014

Para facilitar a aplicação dos questionários e para que os professores pudessem responder as perguntas com privacidade, optou-se pelo desenvolvimento de uma ferramenta digital, no formato de questionário online, ${ }^{1}$ para coleta de dados e geração de gráficos comparativos.

Empregou-se o sistema Google Forms. Questionário disponível em: <goo.gl/H6oOdy> Acesso em: 1 dez. 2016. 
A coleta de dados do Ciclo 2 foi realizada durante o mês de dezembro de 2016, cinco meses após a realização do Ciclo 1. Durante este intervalo, os professores passaram por um processo de atualização que englobou: treinamentos oferecidos por professores da própria instituição; seminários com profissionais externos, cursos sobre diversas tecnologias que dão suporte ao BIM. Isso proporcionou a oportunidade de disseminação de conhecimento específico sobre BIM para os docentes da instituição.

Os professores receberam um e-mail solicitando a realização do questionário online dentro de um prazo pré-estabelecido (uma semana). Findado o prazo, os dados obtidos foram convertidos em planilha para extração de gráficos para apoiar a análise. Os dados coletados foram sintetizados e são apresentados a seguir.

Os questionários foram respondidos por treze professores, que correspondem a $81 \%$ dos docentes do curso técnico, responsáveis pelas treze disciplinas que o compõem. Os dados obtidos foram compilados em gráficos que evidenciam as principais dificuldades dos professores para introduzir o BIM na sua disciplina e no curso como um todo.

Os professores, em sua maioria (69\%), estão atuando há menos de dois anos na disciplina e possuem formação acadêmica dividida entre técnicos (23\%), graduados (31\%), especialistas (31\%) e mestres (15\%) (Gráfico 2).Gráfico 2: Tempo que os professores atuam nas disciplinas (esquerda); formação acadêmica dos professores (direita)

Gráfico 2: Tempo que os professores atuam nas disciplinas (esquerda); formação acadêmica dos professores (direita)
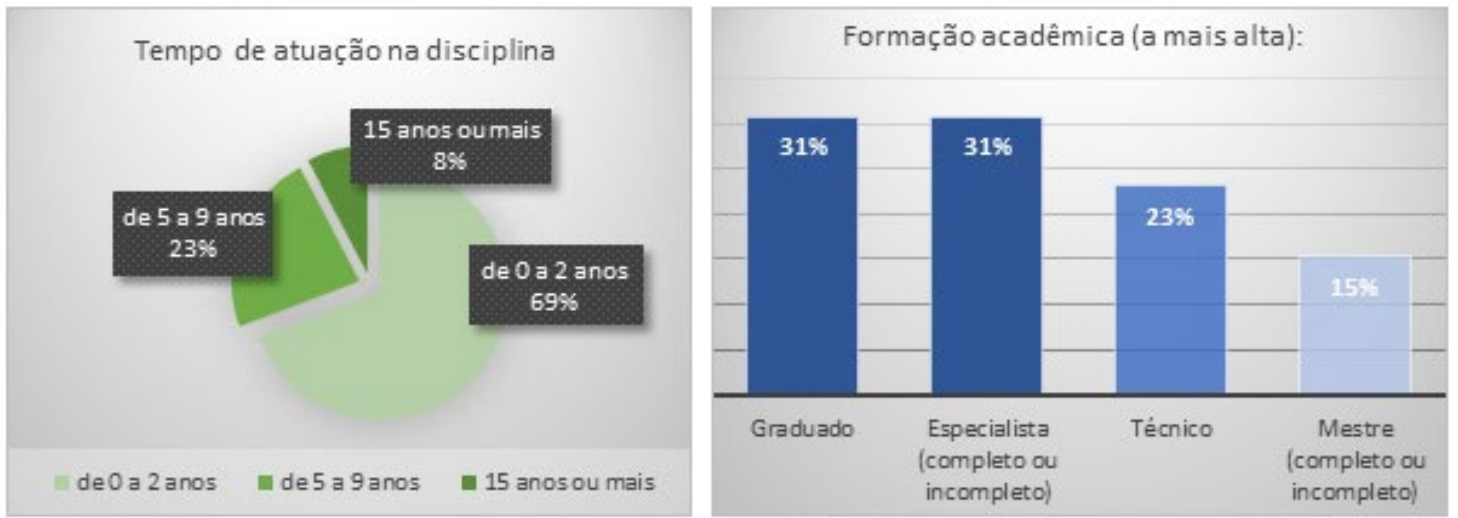

Fonte: os autores

Quando arguidos sobre o interesse em BIM, todos os professores responderam positivamente. A maior parte (92\%) afirmou que na disciplina pode haver interface com BIM, a depender do foco dado pelo professor, e somente $8 \%$ afirmou não haver interface com o tema (Gráfico 3, à esquerda). A maioria (54\%) afirmou já estar aplicando BIM em sua disciplina, 38\% declarou que ainda não estava aplicando e 8\% mencionou que a disciplina não tem relação com BIM (Gráfico 3, à direita).

Gráfico 3: Relação do componente curricular da disciplina com o BIM (esquerda); uso de BIM na disciplina (direita)
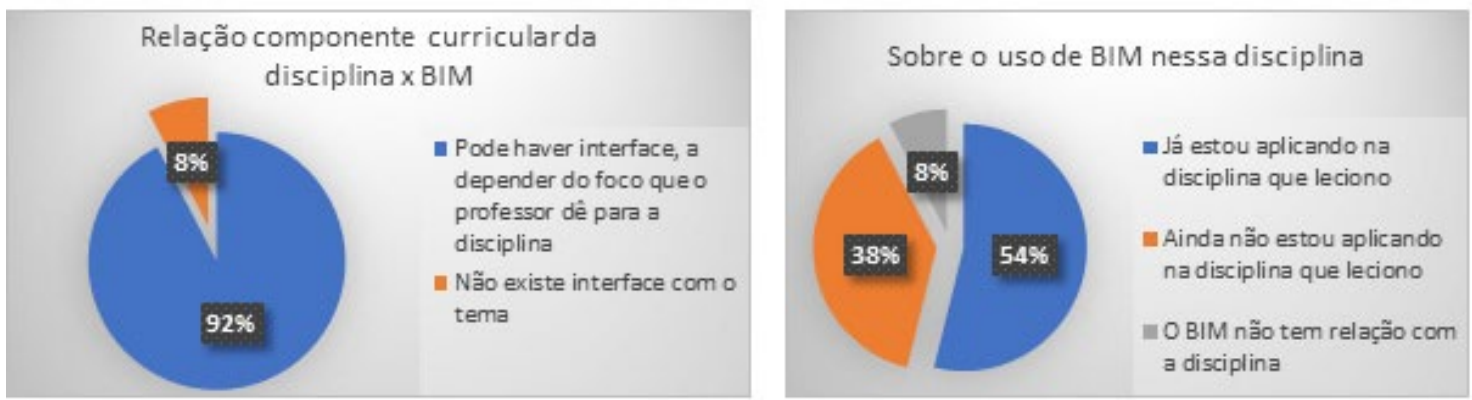

Fonte: os autores 
Os professores apontaram que os conceitos sobre parametrização (92\%), semântica do modelo e modelagem geométrica tridimensional (85\%) são os que mais deveriam ser abordados (Quadro 1, item 2.1), enquanto interoperabilidade seria o conceito menos explorado (54\%) (Gráfico 4). Assim, verifica-se que, embora tenham havido ações prévias para a incorporação de BIM pelos professores, a maturidade necessária para tratar a interoperabilidade ainda não foi atingida, uma vez que para se obter a colaboração, considerando uma visão ampla do ciclo de vida, é necessário abordar questões de interoperabilidade dos modelos.

Gráfico 4: Conceitos BIM que deveriam ou não ser tratados nas diversas disciplinas

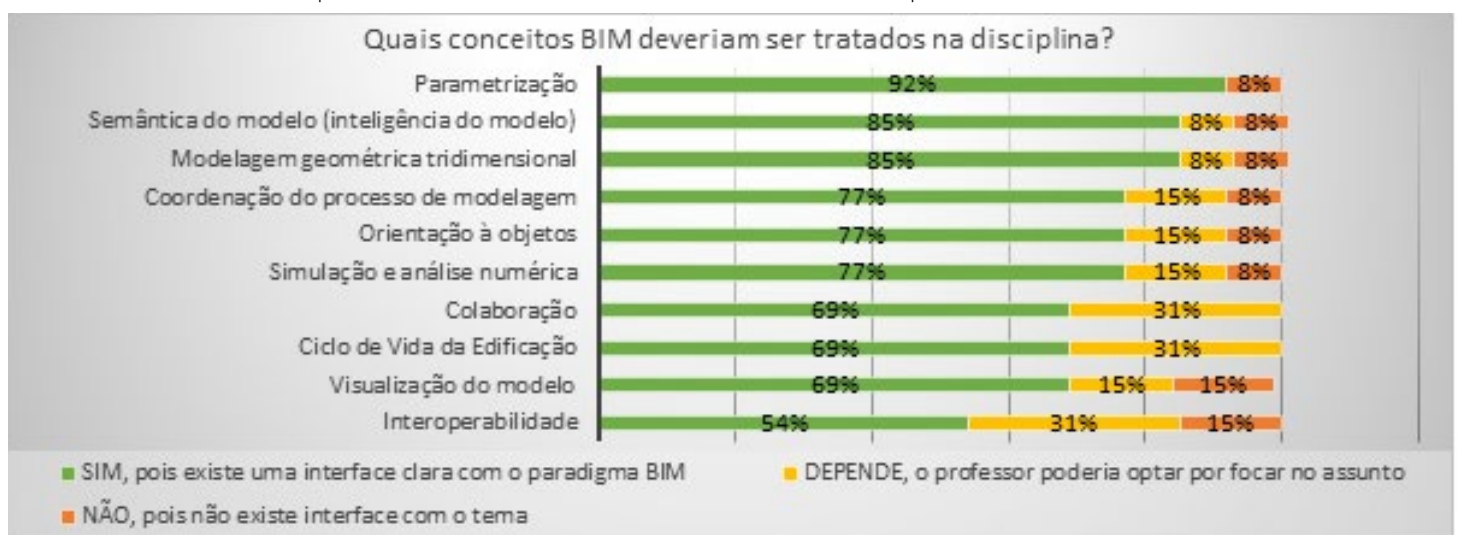

Fonte: os autores

A maioria das disciplinas (77\%) aborda alguma etapa do ciclo de vida da construção, sendo que $8 \%$ afirma que poderia tratar alguma etapa, dependendo do foco dado pelo professor, e 15\% alega não haver relação com este assunto. Das disciplinas que tratam de alguma etapa do ciclo de vida ou que poderiam tratar (Quadro 1, item 2.2), a etapa de construção lidera com $69 \%$ de presença, seguida pela etapa de projetação com $62 \%$, sendo que a etapa de operação e manutenção é a menos abordada, com $23 \%$ de presença (Gráfico 5, à esquerda). Os professores, tendo vivenciado ações para a implementação de BIM no ensino técnico, conseguiram incorporá-lo nas etapas de projeto e construção. Entretanto, verifica-se que existe espaço para ampliar esta incorporação.

O projeto arquitetônico está presente em $69 \%$ das disciplinas que envolvem o desenvolvimento de algum tipo de projeto (Quadro 2, item 2.3), seguido dos projetos estrutural (62\%), elétrico (54\%) e hidráulico (38\%) (Gráfico 5, à direita).

Gráfico 5: Etapas do ciclo de vida da edificação que são ou podem ser tratadas na disciplina (esquerda); averiguação dos tipos de projetos trabalhados nas disciplinas (direita)
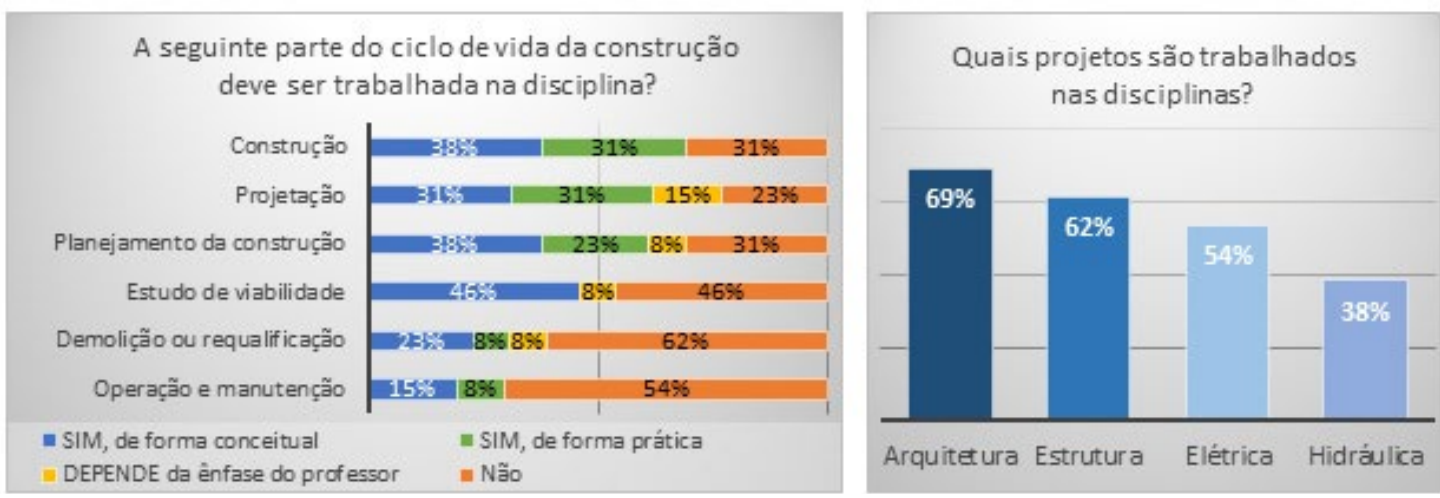

Fonte: os autores 
A maior barreira em implementar BIM nas disciplinas (Quadro 2, item 3.1) foi barreiras culturais (67,5\%), com destaque na falta de conhecimento aprofundado sobre os conceitos BIM (Gráfico 6). Vale ressaltar que, apesar de já terem participado de treinamentos específicos e seminários BIM, os professores ainda indicaram dificuldades em termos de falta de conhecimento específico sobre BIM relacionado à disciplina.

Gráfico 6: Barreiras de inserção de conteúdo sobre BIM na disciplina

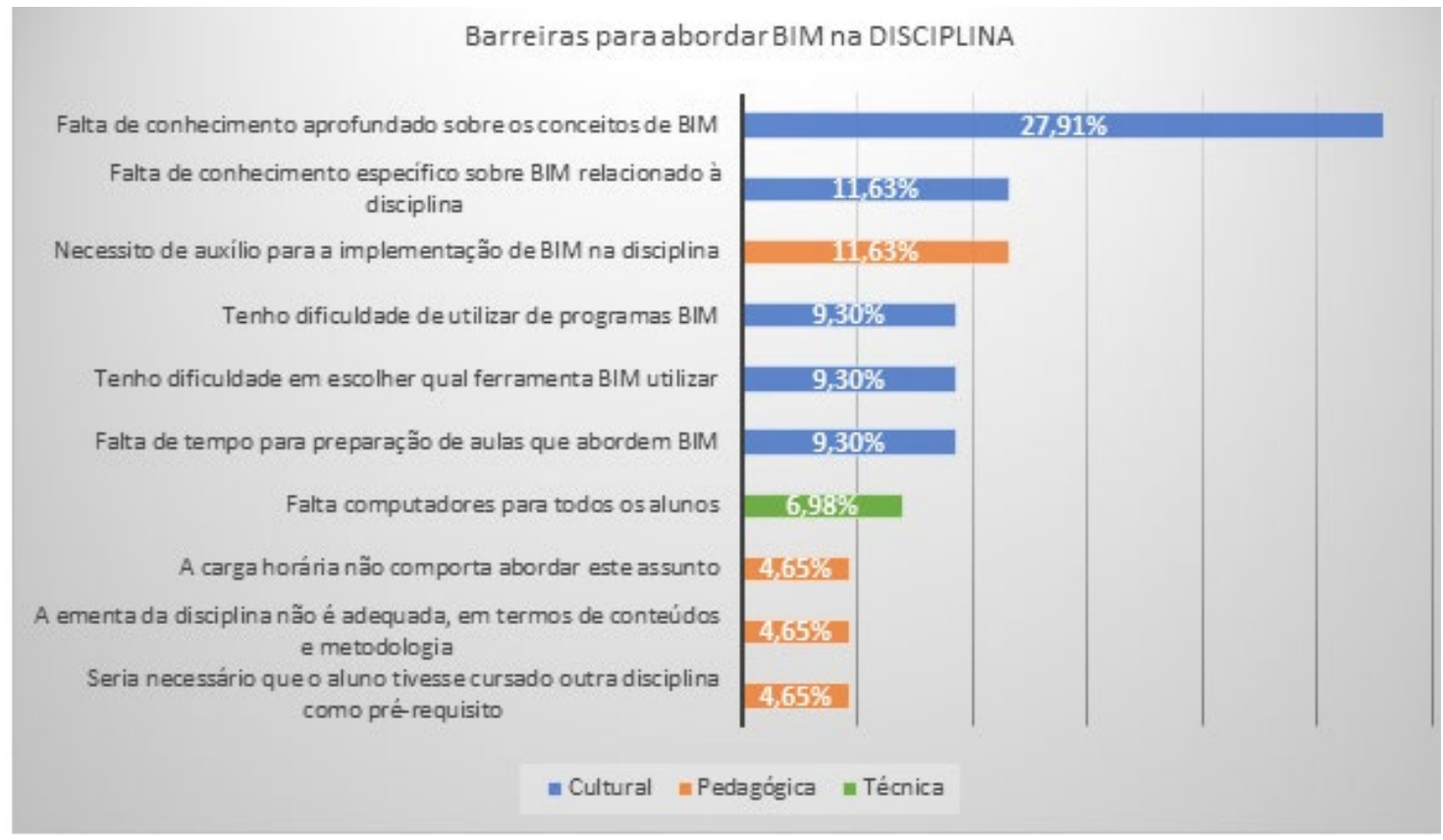

Fonte: os autores

As maiores dificuldades, apontadas pelos professores, em inserir BIM no curso Técnico em Edificações (Quadro 3, item 3.2) reforçam a opinião de que ainda falta conhecimento aprofundado sobre os conceitos que envolvem BIM, uma vez que os professores afirmaram que ainda falta capacitação (36\%). Entretanto, as maiores barreiras para inserção no curso foram pedagógicas (56\%), dentre essas, a falta de materiais didáticos (24\%) e de tempo necessário para amadurecer o currículo (16\%) (Gráfico 7).

Gráfico 7: Dificuldades para implementar BIM no curso técnico em edificações

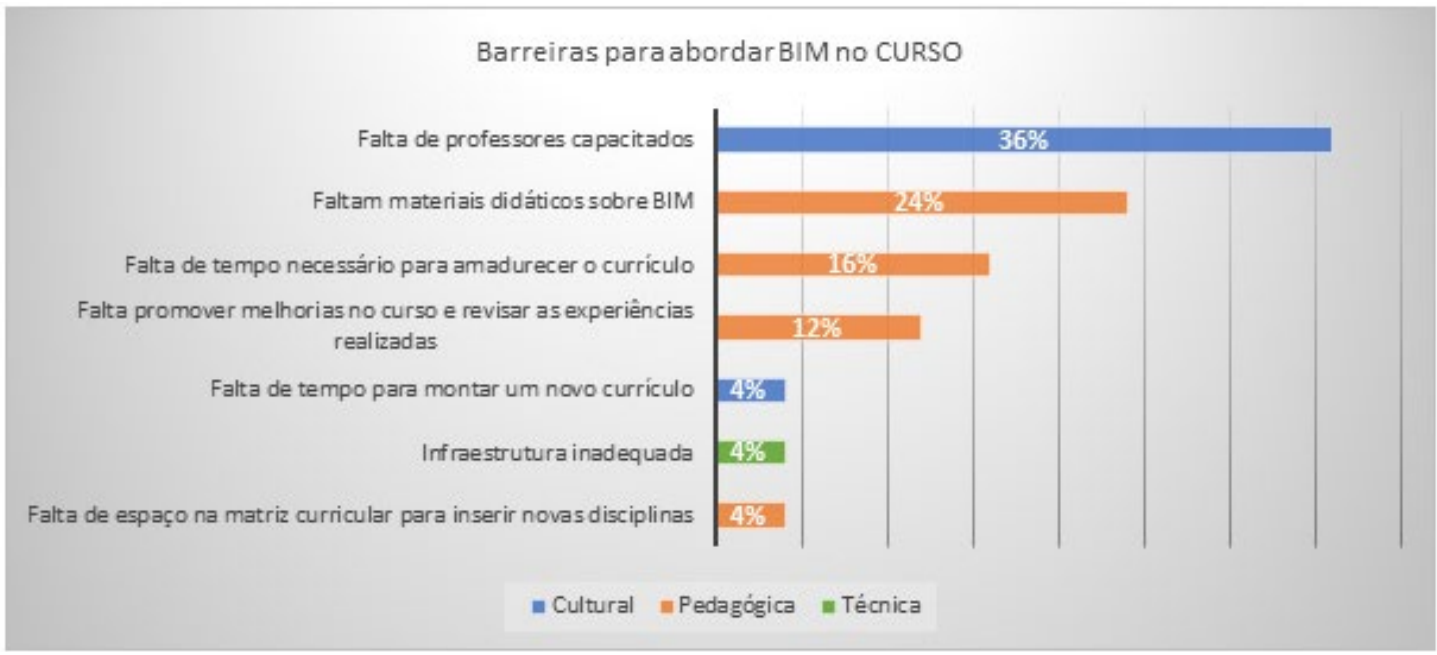

Fonte: os autores 
Corroborando, apesar das ações pela implementação de BIM realizadas pela instituição, a capacitação é o item mais importante para solucionar as dificuldades na inserção de BIM (Quadro 2, item 3.3.), seja pela realização de cursos presenciais (14\%), a distância (11\%) ou por meio de palestras e workshops (14\%). Outro item que merece destaque é o acompanhamento pedagógico periódico do desenvolvimento de projetos que envolvam BIM (11\%) (Gráfico 8).

Gráfico 8: Propostas para solucionar as dificuldades na inserção de BIM

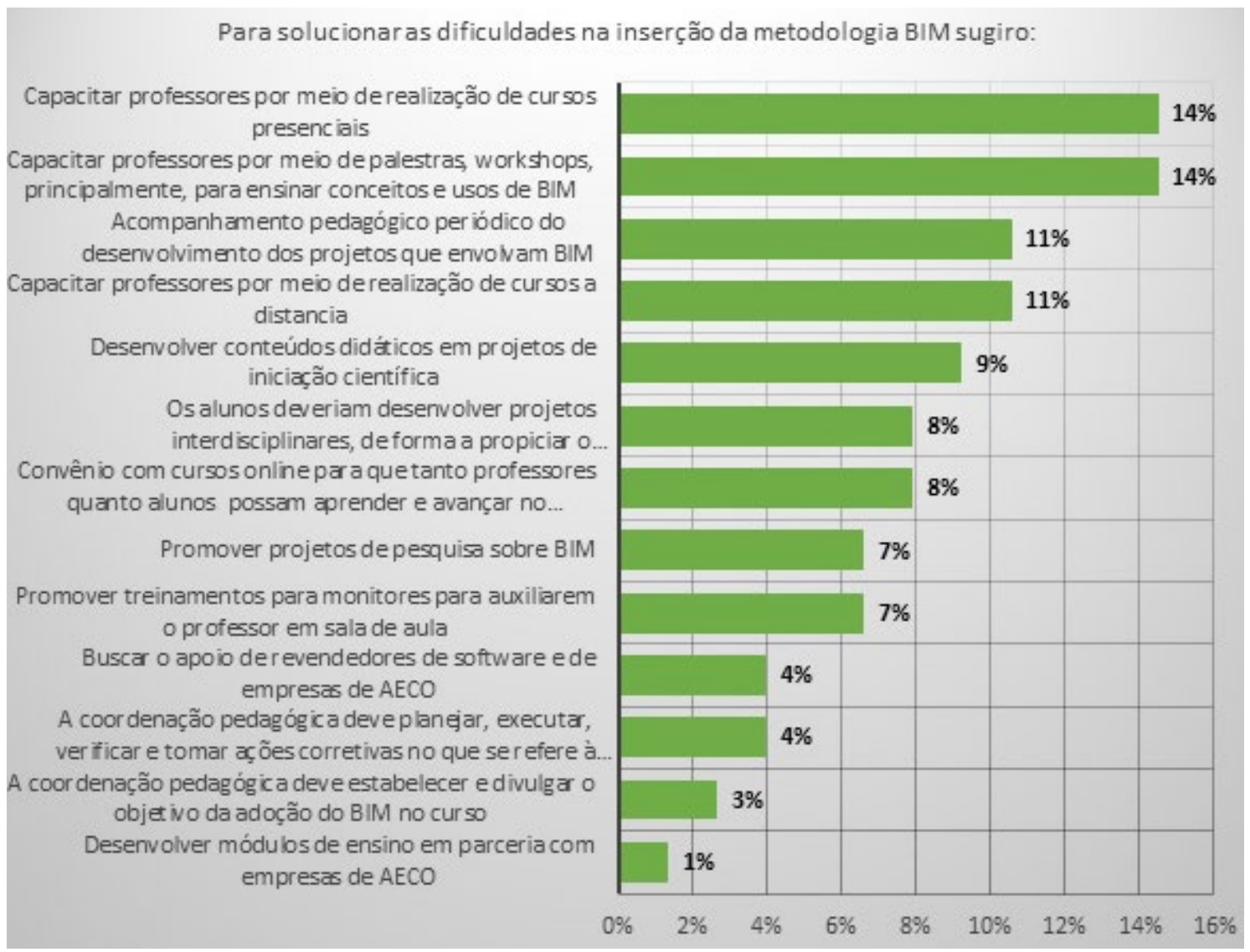

Fonte: os autores

\section{CONSIDERACÕES}

Entre o primeiro e o segundo ciclo de desenvolvimento desta pesquisa decorreram cinco meses, sendo que o diagnóstico mostra o resultado das ações para implementação de BIM realizadas pela escola. Neste intervalo a instituição realizou seminários internos sobre o tema, proporcionou treinamento em vários sistemas (dando liberdade ao professor de escolher qual utilizar) e possibilitou aos professores participarem de congressos sobre o tema. Após os vários seminários ocorridos na unidade, vários docentes apontaram que o tema era mais amplo do que inicialmente imaginado, gerando interesse no assunto. Esse processo fez com que percebessem a importância do tema, possibilitou que os professores observassem como BIM está sendo implementado em outros cursos e como tem sido utilizado em empresas na construção civil.

Esse período coincidiu com um momento de transição, em que os docentes poderiam ou não inserir BIM em suas disciplinas. Antes de aplicar 
em sala de aula, tiveram a chance de utilizar tecnologias que envolvessem BIM. Assim, todos tiveram possibilidade de amadurecer seus conhecimentos sobre o tema, o que aumentou a segurança em tratar o assunto e possibilitou idealizar formas de inserção em suas disciplinas. Na sequência, solicitou-se que as aulas fossem planejadas utilizando BIM tanto conceitualmente como em atividades práticas.

Como exemplo desse processo, destaca-se a disciplina de Instalações Elétricas, na qual, no princípio, o professor assimilou bem o conteúdo teórico, mas não tinha a confiança suficiente para ministrar uma aula prática. A aproximação com tecnologias adequadas, o treinamento específico e o período para investigação das formas de utilização permitiram que, em seguida, o professor pudesse apropriar desse saber em sua disciplina. Corroborando, o entusiasmo de alguns professores, mesmo que de disciplinas não relacionadas à construção civil, como a de Comunicação Oral e Escrita, auxiliaram sua adoção no curso.

Portanto, paralelamente a este processo de pesquisa, houve uma mudança de paradigma na qual os professores começaram a assimilar a importância do tema e de seu conteúdo específico aplicado às diversas disciplinas do curso. Essa mudança de paradigma se refletiu diretamente nas aulas. Durante o processo de transição observou-se a necessidade de alteração das disciplinas, inserindo conteúdo relacionado ao BIM em cada uma delas. Algumas sofreram grande interferência, como a disciplina Representação Gráfica e Documentação Técnica, que teve seu nome alterado para Modelagem Virtual de Edificações e conteúdo integral sobre BIM. A que sofreu menos impacto foi de Ensaios Tecnológicos, uma vez que seu foco é o ensaio em laboratório de materiais de construção.

Além da mudança nas disciplinas, as duas certificações intermediárias oferecidas também foram alteradas. Antes do processo de implementação do BIM, eram denominadas: Laboratorista de Materiais e Desenhista Técnico. Como resultado do processo de implementação, as certificações foram alteradas para: Laboratorista de Materiais e Modelador Virtual de Edificações em nível técnico. A Figura 5 exibe a estrutura curricular alterada do curso.

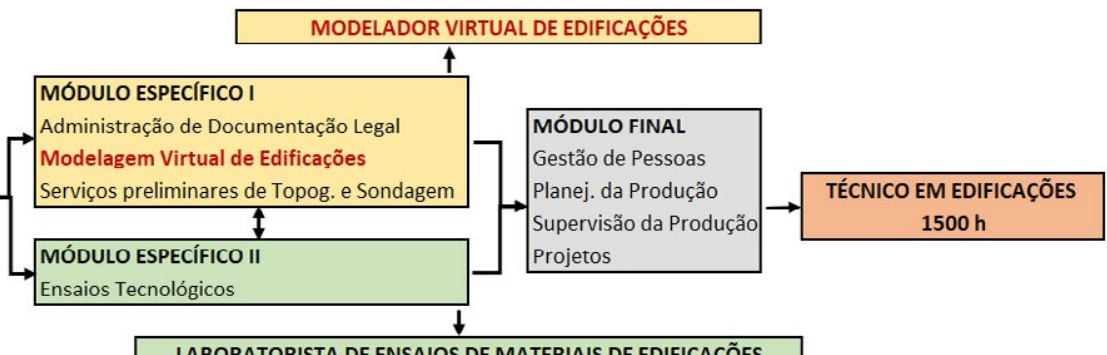

LABORATORISTA DE ENSAIOS DE MATERIAIS DE EDIFICAÇÕES

Figura 5: Estrutura curricular do curso Técnico em Edificações a partir de 2017 (alterações destacadas em vermelho)

Fonte: baseado em Senai, 2017
Com o remodelamento curricular, o plano das disciplinas foi reelaborado, estabelecendo as competências que os alunos terão que adquirir em relação ao BIM. Isso favoreceu também a instituição, que pôde verificar a necessidade de formação continuada dos professores para apoiar o aprimoramento no ensino.

$\mathrm{Na}$ antiga certificação em "Desenhista de Edificações", o aluno estava apto a "participar do projeto da obra (...) representando graficamente os projetos de edificações e seu detalhamento, envolvendo diferentes sistemas construtivos e a documentação legal” (Senai, 2015, p. 27). Entretanto, isto era feito por meio de desenhos 2D e de compatibilização de projetos utilizando ferramentas CAD.

Na atual certificação em “Modelador Virtual de Edificações” a ênfase recai sobre o "desenvolvimento das capacidades técnicas, sociais, organizativas e 
metodológicas relativas à representação gráfica e paramétrica de projetos de edificações e seu detalhamento, envolvendo diferentes sistemas construtivos e suas interfaces" (Senai, 2017, p. 58). Na nova grade curricular, todas as disciplinas envolvidas contêm conceitos BIM e/ou ferramentas computacionais de modelagem, o que permite a nova capacitação.

Com as alterações realizadas no curso, o técnico em edificações aprimorou a compreensão do processo construtivo, uma vez que passou a desenvolver a modelagem BIM de acordo com o que aprende na execução da obra. Ademais, o processo de desenvolver o modelo BIM da edificação faz com que o aluno aprenda mais sobre o processo construtivo e melhore o detalhamento dos projetos.

\section{CONCLUSÕES}

Com esta pesquisa etnográfica foi possível descrever elementos da organização, Escola Senai “Orlando Lavieiro Ferraiuolo", no contexto da incorporação de BIM na formação do técnico de edificações. Os elementos caracterizados foram a transformação na estrutura curricular e a percepção do corpo docente sobre as barreiras associadas. Constatou-se que, na perspectiva do professor, a barreira a ser vencida, individualmente, para a adoção de BIM é a cultural. Entretanto, na perspectiva do conjunto de professores a barreira a ser vencida para adoção de BIM, de forma holística no curso, é a pedagógica.

Observou-se que o objetivo de inserção do BIM no nível de formação básico, segundo a classificação de Checcucci (2014), foi alcançado entre as competências mínimas listadas para este nível. Entretanto, as competências de trabalhar com 4D e de entender conceitos de simulação utilizando modelos BIM ainda podem ser aprimoradas. Por outro lado, competências relacionadas aos outros níveis de formação também estão sendo tratadas no curso, como por exemplo: a criação, a edição e o gerenciamento de famílias de componentes (classificada como competência a nível intermediário) estão sendo tratados na disciplina "Modelagem Virtual da Edificação"; as questões relacionadas à interoperabilidade do modelo (competência classificada como avançada) está sendo tratada na disciplina "Gestão da Produção" e "Planejamento, Custos e Produtividade".

O resultado deste esforço de transformação culminou na remodelagem da estrutura curricular que possibilitou a criação de um novo perfil profissional. Esse profissional está começando a entrar no mercado de trabalho atendendo às novas demandas da indústria. A inserção de técnicos qualificados para a modelagem básica da informação da construção na construção civil corrobora em tornar o mercado mais competitivo, favorecendo o crescimento do setor. Vislumbra-se possibilitar a transformação dos cursos técnicos em edificações e consequente inserção de profissionais mais qualificados no mercado, permitindo novas oportunidades de trabalho. O impacto da inserção de BIM na formação de futuros profissionais para o mercado deve ser observado e analisado.

A implementação do ensino de BIM no curso foi favorecida por alguns fatores primordiais, como: o envolvimento da direção no processo; a transmissão de conhecimento entre os professores da instituição que realizaram treinamento externo e os demais; a participação de profissionais externos à instituição na realização de palestras e consultorias, a adoção de uma abordagem que permitia a utilização de diferentes plataformas pelos professores que atuavam em diversas disciplinas e a realização de cursos específicos.

O processo de incorporação de BIM ainda não foi concluído, mas a Escola Senai “Orlando Lavieiro Ferraiuolo” já está adotando o BIM como estratégia de ensino em todas as suas disciplinas. É importante ressaltar que esse processo envolveu um grupo relativamente pequeno de docentes, 
se comparado ao ensino de graduação. Além disso, a grande inserção de BIM no curso também foi favorecida pelo enfoque mais específico no ensino do curso a nível técnico. Os primeiros resultados da inserção de BIM no ensino, na unidade investigada, influenciaram a gerência regional do Senai-SP que, atualmente, está empenhada em adotar este método nas demais unidades escolares.

As contribuições deste trabalho são o registro do processo e diagnóstico de implementação de BIM no curso técnico em edificações, das ações que possibilitaram o amadurecimento do conhecimento dos professores e a adaptação do método de Checcucci (2014) para diagnóstico da permeabilidade da inserção de BIM em estruturas curriculares. Essa adaptação, em forma de questionário (Quadro 1, 2, 3 e 4), após ser respondido por um número significativo de professores, tem a capacidade de evidenciar a permeabilidade do BIM na estrutura curricular de um curso e seu potencial de aplicação nas diversas disciplinas. Ademais, o método adaptado pode ser aplicado em outras instituições de ensino técnico e, com pequenas modificações, também pode ser utilizado para outros níveis de formação, como nos cursos de graduação em Engenharia Civil e Arquitetura.

\section{AGRADECIMENTOS}

A realização desta pesquisa foi possível graças ao apoio dado pelo Senai-SP, pela Faculdade de Engenharia Civil, Arquitetura e Urbanismo (FEC) da Universidade de Campinas (Unicamp) e à Capes (Coordenação de Aperfeiçoamento de Pessoal de Nível Superior) pela bolsa de Pós-doutorado.

\section{REFERÊNCIAS}

BARISON, M. B. Introdução de Modelagem da Informação da Construção (BIM) no currículo: uma contribuição para a formação do projetista. 2015. 387f. Tese (Doutorado em Engenharia de Construção Civil) - Universidade de São Paulo, São Paulo, 2015.

BARISON, M. B.; SANTOS, E. T. Ensino de BIM: tendências atuais no cenário internacional. Gestão e Tecnologia de Projetos, São Carlos, v. 6, n. 2, p. 67-80, 2011.

CÂMARA BRASILEIRA DA INDÚSTRIA DA CONSTRUÇÃO. Implementação do BIM para construtoras e incorporadoras: parte 1: fundamentos BIM. Brasília, DF: CBIC, 2016.

CHECCUCCl, É. S. Ensino-aprendizagem de BIM nos cursos de graduação em engenharia civil e o papel da expressão gráfica neste contexto. 2014. $235 f$. Tese (Doutorado Multi-institucional e Multidisciplinar em Difusão do Conhecimento) - Faculdade de Educação, Universidade Federal da Bahia, Salvador, 2014.

CHECCUCCI, É. S.; AMORIM, A. L. Método para análise de componentes curriculares: identificando interfaces entre um curso de graduação e BIM. Pesquisa em Arquitetura e Construção, Campinas, v. 5, n. 1, p. 6-17, jan./jun. 2014. Disponível em: <https://goo. gl/B7KBUe>. Acesso em: 17 jan. 2017.
GHAFFARIANHOSEINI, A. et al. Building Information Modelling (BIM) uptake: clear benefits, understanding its implementation, risks and challenges. Renewable and Sustainable Energy Reviews, Amsterdam, v. 75, p. 1046-1053, 2017.

EASTMAN, C. et al. BIM Handbook: a guide to Building Information Modeling for owners, managers, designers, engineers, and contractors. 2. ed. Hoboken: John Wiley \& Sons, 2011. 490p.

GIL, A. C. Como elaborar projetos de pesquisa. 5. ed. São Paulo: Atlas, 2010.

KYMMELL, W. Building Information Modeling: planning and managing construction projects with $4 \mathrm{D} C \mathrm{CAD}$ and simulations. New York: McGraw Hill, 2008.

MCGRAW-HILL CONSTRUCTION. The Business value of BIM for construction in major global markets: how contractors around the world are driving innovation with Building Information Modeling. Bedford: McGraw-Hill Construction Research and Analytics, 2014.

PENTTILÄ, H. Describing the changes in architectural information technology to understand design complexity and freeform architectural expression. Journal of Information Technology in Construction, [s.l.], v. 11, p. 395-408, 2006. 
RUSCHEL, R. C. To BIM or Not to BIM? In: ENCONTRO DA ASSOCIAÇÃO NACIONAL DE PESQUISA E PÓS-GRADUAÇÃO EM ARQUITETURA E URBANISMO, 3., 2014 São Paulo. Anais... São Paulo: Universidade Presbiteriana Mackenzie, 2014

RUSCHEL, R. C.; ANDRADE, M. L. V. X.; MORAIS, M. O ensino de BIM no Brasil: onde estamos? Revista Ambiente Construído Porto Alegre, v. 13, n. 2, p. 151-165, 2013

SACKS, R.; PIKAS, E. Building Information Modeling education for construction engineering and management: I: industry requirements, state of the art, and gap analysis. Journal of Construction Engineering and Management, Reston, v. 139, n. 11, 2013.
SERVICCO NACIONAL DE APRENDIZAGEM INDUSTRIAL. Plano de curso técnico em edificações. São Paulo: Senai, 2013. 90p.

SERVICCO NACIONAL DE APRENDIZAGEM INDUSTRIAL. Plano de curso técnico em edificações. São Paulo: Senai, 2017. 89p.

SUCCAR, B. Building information modeling framework: a research and delivery foundation for industry stakeholders. Automation in Construction, Amsterdam, v. 18, n. 3, p. 357375, 2009. Disponivel em: <https://goo. gl/8UvXAv>. Acesso em: 9 mar. 2017.

SUCCAR, B.; SHER, W.; WILLIAMS, A. Measuring BIM performance: five metrics. Architectural Engineering and Design Management, Abingdon, v. 8, n. 2, p. 120142, 2012.
Ana Cuperschmid anacuperschmid@gmail.com

Marcio de Oliveira Cruz marcio.cruz@sp.senai.br

Regina Coeli Ruschel ruschel@fec.unicamp.br 
